\title{
Assessment of the Personal Hygiene Practices among Primary Schools Children, Sudan: A Cross-Sectional School-Based Study
}

\author{
Mohammed Elmadani ${ }^{1}$, Elham Elamin ${ }^{2}$, Abdelhakam G Tamomh $^{3 *}$ and \\ Peter Twum ${ }^{4}$ \\ ${ }^{1}$ Department of Epidemiology, University of El Imam El Mahdi, Sudan \\ ${ }^{2}$ Department of Hematology, University of El Imam El Mahdi, Sudan \\ ${ }^{3}$ Department of Parasitology and Medical Entomology, University of El Imam El Mahdi, Sudan \\ ${ }^{4}$ College of Health and Well Being, Ghana
}

\section{Research Article \\ Volume 5 Issue 1}

Received Date: December 02, 2020

Published Date: January 06, 2021

DOI: $10.23880 /$ phoa- 16000170

*Corresponding author: Abdelhakam G Tamomh, Department of Parasitology and Medical Entomology, Faculty of Medical Laboratory Sciences, University of El Imam El Mahdi, Kosti, Sudan, Email: abdelhakam738@gmail.com; abdelhakam738@mahdi. edu.sd

\section{Abstract}

The importance of school health has acknowledged across countries since the beginning of the 20th century. Good personal hygiene now forms part of the primary health prevention strategy, and this is effective in reducing morbidity and mortality in children. The current study conducted to assess the personal hygiene practices among primary school children. An observational descriptive cross-sectional facility-based study conducted among 276 pupils during the period from January to February 2016, they were interviewed using a designed pre-tested questionnaire. The study showed that (55.4\%) of school's children keeping their hair clean, (76.1\%) brushing their teeth daily, (60.1\%) pruning their nails, (66.3\%) taking daily bath, (77.2\%) wearing clean clothes, (47.1\%) taking bathing after playing, and all children among study population wearing shoes while coming to school. The boys showed better hand hygiene practices before eating rather than the girls (39.3\% \& $37.6 \%)$, respectively. Statistically, no significant association observed between practices of personal hygiene among study group and educational level of their mothers, and the statistical association observed between (cleaning hair, trimming nails, washing hands after using the toilet) and gender variable $(\mathrm{P}<0.05)$. The results of the current study revealed that a large number of primary school pupils had good personal hygiene. It was also evident that good personal hygiene practices manifested in girls than in boy's ones.

Keywords: Personal Hygiene; School Children; Khartoum State; Sudan

\section{Introduction}

Personal hygiene aims to promote standards of personal cleanliness within the setting of the condition where people live [1]. Personal hygiene includes bathing, clothing, washing hands after toilet, care of nails, feet, and teeth; spitting, coughing, sneezing, personal appearance, and healthy habits inculcation in the young people [2,3]. Personal hygiene training should start at a very young age and should continue through school-age [4,5]. Also, it recognized that improved personal hygiene is effective in preventing transmission of many diseases [6-9]. According to the World Health Organization (WHO), about two million people every year die due to diarrheal diseases [10]. The majority of deaths occur among children under the age of five years [11]. Hygiene practices prevent or minimize disease and the spreading of disease. The microbial growth due to germs may lead to various infectious diseases among children $[12,13]$. Since 
the beginning of the 20th century, the importance of school health has been recognized across countries [14]. The condition of school health may be worse in communities with poor socio-economic conditions and deteriorated living situations $[15,16]$.

Good personal hygiene is now part of the primary health prevention strategy; it has been proven effective in reducing childhood morbidity and mortality $[17,18]$. School is the place where health education granted about crucial aspects of hygiene, environment, and sanitation, as well as social customs $[19,20]$. UNICEF has published extensive material on school sanitation and hygiene intended at facilitating that learners be agents of change as they live in the community. It achieved by evaluation of the hardware aspects, such as the physical infrastructure, sanitation facilities at schools and the availability of safe water [21]. Based on the Multiple Indicator Cluster Survey (MICS) in Sudan 2014, only (32.9\%) of Sudanese household members used a non-shared improved sanitation facility [22], and that means two-third of people living in worse sanitation condition. Therefore, this current study aimed to assess the personal hygiene practices among primary school Sudanese children to explore their health status and distinguish their personal hygiene practices.

\section{Materials and Methods}

\section{Study Design}

A school-based cross-sectional quantitative study conducted among primary school children in the peripheral site of Karari locality, Omdurman city, Khartoum state, Sudan to asses personal hygiene practices among school children. The study included students from class one to class eight during the period from January to February 2016.

\section{Sampling Technique}

Systematic randomizing sampling design employed as the sampling method where the number of students from the registry data of school taken as the study population (891), and dividing by sampling frame size (276), then randomly selected starting point by listing number from 1 to 10 and used fixed periodic interval (3) to obtain desired sample size. The sample size based on a total of the population has calculated according to the Slovin formula and the sample size estimates (276) participants, and all covered by study with full a structured questionnaire.

\section{Method of Data Collection}

A pilot study involving ten students was carried out at the school understudy to test the reliability and validity of the questionnaire. The designed questionnaire was modified, based on the results of the pilot study. The group of students who tested in the pilot study excluded from the total study sample. Before data collection, an appointment with the school's director and school teachers took place to introduce them to how they can help students to fill out the questionnaire. Data were collected using a structured pre-tested questionnaire with the participation of school teachers and reviewed by the researcher which includes the socio-demographic variables such as (age group, sex, etc) and other variables such as (clean of hands, brushing teeth, bathing, etc).

\section{Data Analysis}

Analysis of data carried using statistical package for social sciences (SPSS) version 23. The data presented in tables and figures as frequency and percentage. The difference between variables checked using the Chi-Square test, and the Probability value less than $0.05(\mathrm{p}<0.05)$ considered significant.

\section{Ethical Considerations}

The study protocol reviewed and approved by the Public Health Research Board, University of El Imam El Mahdi, and White Nile State, Sudan.

\section{Results}

The demographic and socioeconomic characteristics variables of the primary school children who participated in this study as follows; Two hundred and seventy-six primary school children enrolled in the present study. Boys were 150 $(54.3 \%)$ and the girls are $126(45.7 \%)$ as shown in Figure 1.

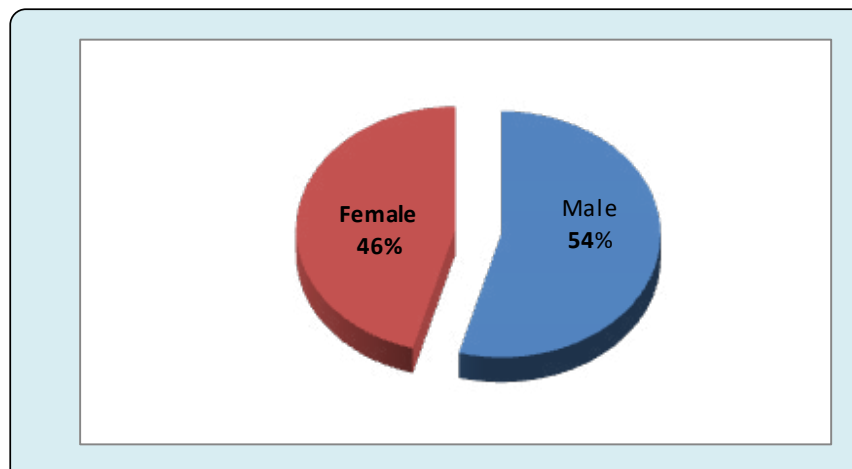

Figure 1: Gender distribution among study participants.

An estimate of maternal and household Illiterate were $(17 \%)$ and $(8 \%)$ respectively. $(12.7 \%)$ of children age was less than eight years, (46.7\%) from 8-11 years, and $(40.6 \%)$ is more than 12 years as expressed in Figure 2. The distribution of personal hygiene practices among study 
subjects presented in Table1. Statistically, no significant association observed between practices of personal hygiene among study group and educational level of their mothers. The Association between wearing clean clothes and different demographic variables was explained in Table 2. The statistical association observed between (cleaning hair, trimming nails, washing hands after using the toilet) and gender variable $(\mathrm{P}<0.05)$.

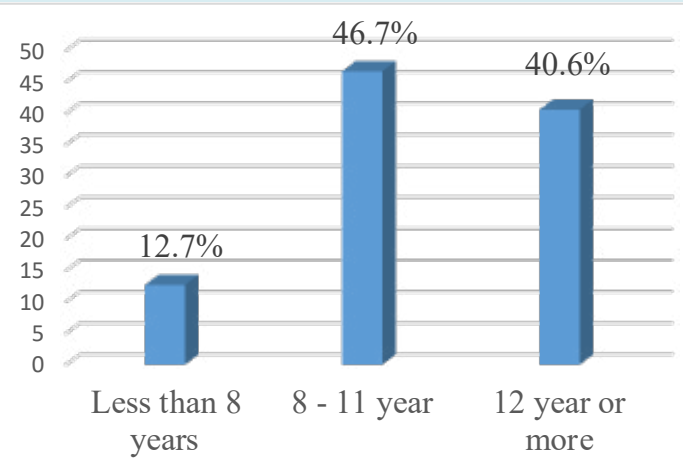

Figure 2: Distribution of age groups among study participants.

\begin{tabular}{|c|c|c|c|c|c|}
\hline Indicator & Always (M/F)\% & Frequently(M/F)\% & Sometimes(M/F)\% & Never(M/F)\% & $*$ P-Value \\
\hline Daily Brushing & $112(74.7) / 98(77.8)$ & $20(13.3) / 17(13.5)$ & $17(11.3) / 11(8.7)$ & $1(0.7) / 0(0.0)$ & 0.709 \\
\hline Cutting Nails & $94(62.7) / 72(57.1)$ & $49(32.7) / 34(26.9)$ & $7(4.7) / 18(14.3)$ & $0(0.0) / 2(1.6)$ & 0.015 \\
\hline Wear Clean Clothes & $112(74.7) / 101(80.2)$ & $29(19.3) / 23(18.3)$ & $7(4.7) / 2(1.6)$ & $2(1.3) / 0(0.0)$ & 0.263 \\
\hline Daily Bathing & $99(66) / 84(66.7)$ & $42(28) / 40(31.7)$ & $9(6) / 2(1.6)$ & $0(0.0) / 0(0.0)$ & 0.159 \\
\hline Cleaning Hair & $86(57.3) / 67(53.2)$ & $49(32.7) / 33(26.2)$ & $14(9.3) / 9(7.1)$ & $1(0.7) / 17(13.5)$ & $<0.001$ \\
\hline Washing Hands After Toilet & $50(33.3) / 65(51.6)$ & $34(22.7) / 31(24.6)$ & $59(39.3) / 23(18.3)$ & $7(4.7) / 7(5.6)$ & $<0.001$ \\
\hline $\begin{array}{c}\text { Washing Hands Before } \\
\text { Eating }\end{array}$ & $108(72) / 104(82.5)$ & $27(18) / 16(12.7)$ & $14(9.3) / 6(4.8)$ & $1(0.7) / 0(0.0)$ & 0.169 \\
\hline
\end{tabular}

Table 1: Distribution of personal hygiene practices among study subjects $(n=276)$.

M- Male, F- Female, $\%$ - percent, ${ }^{*} p<0.05$ was considered statistically significant.

\begin{tabular}{|c|c|c|c|c|c|c|}
\hline \multirow{2}{*}{ Variables } & \multicolumn{6}{|c|}{ Wear Clean Clothes } \\
\hline & Always (\%) & Frequently (\%) & Sometimes (\%) & Never (\%) & Total (\%) & *P-Value \\
\hline \multicolumn{7}{|c|}{ Education Of Child-Mother } \\
\hline Graduate & $54(19.7)$ & $13(4.8)$ & $8.0(2.8)$ & $1.0(0.3)$ & $76(27.6)$ & \multirow{3}{*}{0.233} \\
\hline Basic/Secondary School & $125(45.3)$ & $19(6.8)$ & $9.0(3.4)$ & $0.0(0.0)$ & $153(55.5)$ & \\
\hline Illiterate & $33(11.9)$ & $11(3.9)$ & $3.0(1.1)$ & $0.0(0.0)$ & $47(16.9)$ & \\
\hline \multicolumn{7}{|c|}{ Occupation Of Household } \\
\hline Work & $190(69)$ & $49(17.7)$ & $9(3)$ & $1(0.3)$ & $249(90)$ & \multirow{2}{*}{0.12} \\
\hline Not Work & $23(8.7)$ & $3(1)$ & 0 & $1(0.3)$ & $27(10)$ & \\
\hline \multicolumn{7}{|c|}{ Number Of Family Members } \\
\hline Less Than 6 Members & $38(14)$ & $14(5.4)$ & $2(0.6)$ & $0(0.0)$ & $54(20)$ & \multirow{3}{*}{0.181} \\
\hline 6 Members & $43(15.4)$ & $3(1)$ & $1(0.3)$ & $1(0.3)$ & $48(17)$ & \\
\hline More Than 6 Members & $132(48)$ & $35(12.7)$ & $6(2)$ & $1(0.3)$ & $174(63)$ & \\
\hline
\end{tabular}

Table 2: Association Between Wearing Clean Clothes and Different Demographic Variables $(\mathrm{n}=276)$.

(\%) - percent, ${ }^{*} p<0.05$ considered statistically significant 


\section{Discussion}

The demographic and socioeconomic characteristics variables of the primary school children who participated in this study as follows; Two hundred and sixty-seven primary school children enrolled in the present study. Boys were $150(54.3 \%)$ and the girls are 126 (45.7\%). An estimate of maternal and household illiterate were (17\%) and (8\%) respectively. (12.7\%) of children, age was less than eight years, (46.7\%) from 8-11 years, and (40.6\%) are more than 12 years old. This study finds that $76.8 \%$ always washing their hand before eating, $41.7 \%$ always washing hand after toilet, $55.4 \%$ always clean their hair, $66.3 \%$ always have daily bathing, $77.2 \%$ always wearing clean clothes when they come to school, $76.1 \%$ always brushing their teeth daily, $60.1 \%$ always cutting their nails, $47.1 \%$ always bathing after playing and all study group wearing shoes when they come to school. The current study showed that the children who were always washing their hands with soap before eating were (76.8\%), while $(0.4 \%)$ never wash their hands with soap before eating; (41.7\%) of student were washed their hand with soap after using the toilet and it is a little percent due to lack of facilities and hygienic materials beside the toilets. Comparing to study conducted by Arikan, 2014 "(94.2\%) reported that they are washing their hands with soap after using the toilet and $(75.1 \%)$ reported that they are washing their hands with soap before the meals" [8]. Current study showed that (55.4\%) of school's children keeping their hair clean, $(76.1 \%)$ brushing their teeth daily, $(60.1 \%)$ pruning their nails, (66.3\%) taking daily bath, $(77.2 \%)$ wearing clean clothes, (47.1\%) bathing after playing, and all children among study population wearing shoes while coming to school. These observations indicate that hygienic practices for all the indicators of personal hygiene were not corrupt but it needs more effort to encourage students for more hygienic practices. A study conducted in India indicated that (94.23\%) of primary school children washed their hands after visiting the toilet and (84.62\%) washed their hands before eating, and this is more than what mentioned in the current study. Also (48.08\%) combed their hair, (50\%) brushed their teeth, $(76.92 \%)$ trimmed their nails, $(42.31 \%)$ took a daily bath, (55.77\%) wore shoes, and only (12.5\%) wore clean clothes [15]. Also, a study conducted in Ghana found that only (5\%) washed their hands before eating. None of the respondents washed hands after the toilet, with (7\%) washing their hands after eating [23]. Another study carried out in Ethiopia showed, only (36.2\%) of students who washed their hands reported using soap after defecation [24]. Well, the study took place in Bagdad showed that (56\%) of student washing their hands before eating and (91\%) after using the toilet [25].

In the present study, girls showed better hand hygienic practices than boys before eating (83\% \& 72\%) respectively, in the other hand, girls indicated healthier hands practices after using the toilet (51.6\%) compared with (33.3\%) for boys because the girls give more attention to their appearance and also help mothers cooking at home; for that, they keep hands clean. In the study conducted in northern India, the girls had better handwashing practices than the boys before eating at home ( $70.4 \%$ vs. $56.3 \%)$, as well as at school (92.6\% vs. 79.6\%) [11]. In the present study, (0.4\%) of pupils had poor hands hygiene before eating and (5.1) after using the toilet. Another study conducted in India 2013 , it was found that (65.9\%) of girls had good personal hygiene compared to boys (60.5\%), and about (28.8\%) of boys had poor personal hygiene, compared to girls $(25.5 \%)$ [14]. The statistical association observed between cleaning hair, trimming nails, washing hands after using toilet and gender $(\mathrm{P}<0.05)$ and this is due to the continued interest of girls in their appearance and their stay at home for more extended periods rather than boys, therefore, they have more care to themselves. Statistically, there is no significant association observed between personal hygiene practices among primary school children and the educational level of their mothers.

\section{Limitation of the Study}

The limitation of this current study is that it did not cover several schools due to inadequate material resources and lack of funding.

\section{Conclusion}

This study aimed to assess the personal hygiene practices among primary school children. This result revealed that a large number of primary school pupils had good personal hygiene. It was also evident that good personal hygiene practices manifested in girls than in boy's ones.

\section{Competing Interests}

The authors declare that they have no competing interests.

\section{Funding}

None

\section{Acknowledgements}

Not applicable

\section{References}

1. Paul KK, Panigrahi SK, Soodi RAK, Sahu T (2017) Association of personal hygiene with common 


\section{Public Health Open Access}

morbidities among upper primary school children in rural Odisha. J Family Med Prim Care 6(3): 509-512.

2. Holt GR (2012) Importance of personal hygiene techniques in public health. South Med J 105(1): 5.

3. Gawai PP, Taware AS, Chatterjee SA, Thakur H (2016) A cross sectional descriptive study of hand washing knowledge and practices among primary school children in Mumbai, Maharashtra, India. IJCMPH 3(10): 29582966.

4. Saffari M, Koenig HG, Pakpour AH, Sanaeinasab H, Jahan HR, et al. (2014) Personal hygiene among military personnel: developing and testing a self-administered scale. Environ Health Prev Med 19(2): 135-142.

5. Kasaei R, Carmena D, Jelowdar A, Beiromvand M (2018) Molecular genotyping of Giardia duodenalis in children from Behbahan, southwestern Iran. Parasitol Res 117(5): 1425-1431.

6. Dangour AD, Watson L, Cumming O, Boisson S, Che Y, et al. (2013) Interventions to improve water quality and supply, sanitation and hygiene practices, and their effects on the nutritional status of children. Cochrane Database Syst Rev (8): Cd009382.

7. Cairncross S, Hunt C, Boisson S, Bostoen K, Curtis V, et al (2010) Water, sanitation and hygiene for the prevention of diarrhoea. Int J Epidemiol 39 (S1): i193-i205.

8. Arikan I, Dibeklioglu SE, Arik O, Gulcan A (2014) Personal hygiene status among primary school students in an urban area in the west of Turkey. American Journal of Research Communication 2(7): 23-36.

9. Soleymani MR, Hemmati S, Ashrafi-Rizi H, Shahrzadi L (2017) Comparison of the effects of storytelling and creative drama methods on children's awareness about personal hygiene. J Educ Health Promot 6: 82.

10. Petersen PE (2009) Global policy for improvement of oral health in the 21st century--implications to oral health research of World Health Assembly 2007, World Health Organization. Community Dent Oral Epidemiol 37(1): 1-8.

11. Sekhon H, Minhas S (2014) A school based survey on hygiene in a rural area of northern India. International Journal of Pharma Research and Health Sciences 2(2): 179-184

12. Paliwal V, Paliwal C, Chatuvedi S (2014) Personal Hygiene Habits among School-Going Children in Rural Areas of
Jaipur, Rajasthan, India. IJSRR 3(2): 126-142.

13. Mehta A, Kaur G (2012) Oral health-related knowledge, attitude, and practices among 12-year-old schoolchildren studying in rural areas of Panchkula, India. Indian J Dent Res 23(2): 293.

14. Motakpalli K, Indupalli AS, Sirwar SB, Jayaalakshmi KN, Bendigeri ND, et al (2013) A study on health hygiene among school children in rural field practice area of ajims mangalore in karnataka: india. International Journal of Bioassays 2(10): 1407-1410.

15. Sarkar M (2013) Personal hygiene among primary school children living in a slum of Kolkata, India. J Prev Med Hyg 54(3): 153-158.

16. Richmond JB, Kotelchuck M (1984) Personal health maintenance for children. West J Med 141(6): 816-823.

17. Ahmadu BU, Rimamchika M, Ibrahim A, Nnanubumom AA, Godiya A, et al. (2013) State of personal hygiene among primary school children: A community based cohort study. Sudan J paediatr 13(1): 38-42.

18. Luby S, Agboatwalla M, Schnell BM, Hoekstra RM, Rahbar MH, et al. (2002) The effect of antibacterial soap on impetigo incidence, Karachi, Pakistan. Am J Trop Med Hyg 67(4): 430-435.

19. Ghanim M, Dash N, Abdullah B, Issa1 H, Albarazi R, et al. (2016) Knowledge and Practice of Personal Hygiene among Primary School Students in Sharjah-UAE. Journal of Health Science 6(5): 67-73.

20. Dongre A, Deshmukh P, Boratne D, Thaware P, Garg B (2008) An approach to hygiene education among rural Indian school going children. Online J Health Allied Scs 6(4): 1-6.

21. Sibiya JE, Gumbo JR (2013) Knowledge, Attitude and Practices (KAP) Survey on Water, Sanitation and Hygiene in Selected Schools in Vhembe District, Limpopo, South Africa. Int J Environ Res Public Health 10(6): 2282-2295.

22. Statistics, O moccb (2015) Sudan Multiple Indicator Cluster Survey (MICS), Khartoum: Bureau of Statistics in collaboration with the Ministry of Health.

23. Steiner AM, Van ESE, Papoe M, Setorglo J, Asiedu DK, et al. (2011) Hand Washing Practices among School Children in Ghana. Current Research Journal of Social Sciences 3(4): 293-300.

24. Vivas A, Gelaye B, Aboset N, Kumie A, Berhane Y, et al. (2010) Knowledge, Attitudes, and Practices (KAP) of 
Hygiene among School Children in Angolela, Ethiopia. J Prev Med Hyg 51(2): 73-79.

25. Aburaghif LF (2015) Personal Hygiene Perception among School-Age Children in Baghdad City/ Resafa Side. IOSR Journal of Nursing and Health Science (IOSRJNHS) 4(5): 2320-1940.

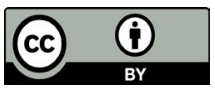

